\title{
Inactivation and Disinfection of Zika Virus on a Nonporous Surface
}

Cameron Wilde', Zheng Chen ${ }^{1}$, Tanya Kapes ${ }^{1}$, Cory Chiossone', Salimatu Lukula', Donna Suchmann'1, Raymond Nims ${ }^{2}$ and S Steve Zhou' ${ }^{1 *}$

${ }^{1}$ MicroBioTest, A division of Microbac Laboratories, Sterling, VA, USA

${ }^{2}$ RMC Pharmaceutical Solutions, Inc., Longmont, CO, USA

\begin{abstract}
The zika virus (ZIKV), an emergent arbovirus within the flavivirus family, is of public health concern due to the lack of a vaccine and possibility of teratogenic effects in infected pregnant women. The flaviviruses are enveloped, and it might be expected that inactivation methods for enveloped viruses in general might be effective for ZIKV. We have investigated a number of physical and chemical inactivation approaches using both low protein (5\% serum) and $90 \%$ blood organic loads present during drying of virus onto carriers. ZIKV in $90 \%$ blood displayed $\sim 0.06$ log $_{10}$ per hour inactivation over $8 \mathrm{~h}$, while virus in $5 \%$ serum was inactivated at a much higher rate $\left(\sim 0.5 \log _{10}\right.$ per h). ZlKV was susceptible to dry heat treatment $\left(56^{\circ} \mathrm{C}-60^{\circ} \mathrm{C}\right)$ when dried in $5 \%$ serum, but less so when dried in $90 \%$ blood. A quaternary ammonium/alcohol-based product and $70 \%$ isopropyl alcohol caused complete $\left(>3.5\right.$ and $>5$ log $_{10}$ respectively) inactivation of ZIKV in $15 \mathrm{~s}$ regardless of the organic load. Efficacy of inactivation of ZIKV by chlorine was highly dependent on the organic load at time of drying, with complete $\left(>4 \log _{10}\right)$ inactivation being observed in $15 \mathrm{~s}$ by $500 \mathrm{ppm}$ chlorine at $5 \%$ serum. Inactivation in the presence of $90 \%$ blood required 5,000 ppm chlorine to achieve $>2 \log _{10}$ inactivation, and 10,000 ppm chlorine to achieve $>3 \log _{10}$. Peracetic acid (1,000 ppm) inactivation also displayed a striking dependence on organic load, with complete $\left(>4 \log _{10}\right)$ inactivation observed in $15 \mathrm{~s}$ at $5 \%$ serum and $<1.5 \log _{10}$ reduction in 5 minutes in a $90 \%$ blood matrix. When suspended in solutions of $\mathrm{pH} 4.0 \mathrm{or} \mathrm{pH}$ 10.0 at time of drying, ZIKV displayed $<1.5 \log _{10}$ reduction in $5 \mathrm{~min}$, regardless of organic load. In conclusion, ZIKV displays susceptibility to commonly employed disinfectants similar to that of other flaviviruses.
\end{abstract}

Keywords: Zika virus; BVDV; West Nile virus; Inactivation; Disinfectant; Enveloped virus; Organic load

\section{Introduction}

The flavivirus bovine viral diarrhea virus (BVDV, genus Pestivirus) has been used in inactivation studies as a model virus for other flaviviruses such as hepatitis C (genus Hepacivirus). Inactivation data have not, until very recently, been collected and reported for the newly emergent flavivirus Zika virus (ZIKV; genus Flavivirus). These data are needed in order to assure the adequate sanitization of research laboratories and healthcare facilities handling specimens obtained from patients infected with ZIKV. It has been reported that ZIKV has multitissue tropism, having been isolated from the blood, saliva, urine, semen, and female genital tract secretions of infected individuals [1-5]. The arbovirus may also be present on environmental surfaces exposed to such fluids. The virus represents a threat to the blood supply as it may be transmitted through blood transfusions. These factors, combined with the survivability of the virus in vitro, may create opportunistic infections independent of the natural route of transmission through mosquito bites. There have been reports of sexual-transmission of ZIKV [6-8]; and of lab-acquired ZIKV infection [9]. It is therefore important to characterize the effectiveness of various disinfectants and physical approaches for inactivating ZIKV. Such knowledge may help guide healthcare workers and laboratory researchers, enabling them to handle the virus more safely, and may help the general public to reduce the risk of fluid-acquired infection. Knowledge of the stability of ZIKV and its resistance to any disinfectants may help understand better the structure of the virus and viral-matrix interactions.

The present study was conducted in order to provide information on the environmental stability of ZIKV on hard, non-porous surfaces such as glass, and to provide inactivation efficacy information for some commonly employed physical and chemical (disinfectant) inactivation approaches. Since ZIKV may be grown in cell culture in a laboratory, or may be associated with blood or other bodily fluids in nature, the impact of organic load in ZIKV inactivation and disinfection was assessed. In addition, we have examined the similarities in inactivation susceptibility of ZIKV and other flaviviruses (BVDV and WNV) for which inactivation efficacy results have been reported previously in the literature.

\section{Materials and Methods}

\section{Reagents defibrinated}

Sheep blood was from Cocalico Biologicals, Inc. (Reamstown, PA), Gibco ${ }^{\mathrm{Tm}}$ fetal bovine serum (FBS) and isopropyl alcohol were from ThermoFisher Scientific, chlorine (sodium hypochlorite solution), peracetic acid, and a proprietary quaternary ammonium/alcohol-based product were obtained commercially. Low and high $\mathrm{pH}$ inactivation solutions were prepared as follows: $2.5 \mathrm{~N}$ hydrochloric acid or $1.0 \mathrm{~N}$ sodium hydroxide solutions were added to sterile deionized water $+1 \%$ bovine serum albumin solution until the $\mathrm{pH}$ reached 4.0 and 10.0, respectively.

\section{Viruses}

Zika virus (strain PRVABC59) was obtained from the Centers for Disease Control and Prevention (CDC). The identity of the virus was confirmed by analysis of viral RNA using primers targeting the ZIKV virus capsid protein gene (GenBank accession number AMC13911). The virus was diluted in Minimum Essential Medium (MEM) $+5 \%$ fetal bovine serum (FBS) and added to T-75 flasks of Vero E6 cells. The flasks

*Corresponding author: S Steve Zhou, MicroBioTest, a division of Microbac Laboratories, Sterling, USA, Tel: +1 571-926-8216; E-mail: steve.zhou@microbac.com

Received September 16, 2016; Accepted September 28, 2016; Published October 06, 2016

Citation: Wilde C, Chen Z, Kapes T, Chiossone C, Lukula S, et al. (2016) Inactivation and Disinfection of Zika Virus on a Nonporous Surface. J Microb Biochem Technol 8: 422-427. doi: 10.4172/1948-5948.1000319

Copyright: $(2016$ Wilde $\mathrm{C}$, et al. This is an open-access article distributed under the terms of the Creative Commons Attribution License, which permits unrestricted use, distribution, and reproduction in any medium, provided the original author and source are credited. 
were incubated at $36^{\circ} \mathrm{C}$ for 90 min to allow for viral adsorption after which they were riffed with MEM $+5 \%$ FBS. The flasks were incubated at $36^{\circ} \mathrm{C}$ until $\sim 90 \%$ of the cells exhibited viral cytopathic effect (CPE; Figures 1 and 2). The flasks were frozen at $-80^{\circ} \mathrm{C}$ and then thawed at ambient temperature. The conditioned medium was collected and clarified at 2,000 rpm for $15 \mathrm{~min}$ and the resulting supernatant was aliquoted and stored at $-80^{\circ} \mathrm{C}$ until use. The certified titer of the stock ZIKV was determined to be 7.25-7.50 $\log _{10}$ tissue culture infectious dose $_{50}$ per $\mathrm{mL}\left(\mathrm{TCID}_{50} / \mathrm{mL}\right)$ in Vero E6 cells.

Bovine viral diarrhea virus (BVDV), strain NADL, was obtained from American BioResearch Laboratories, Inc. (Pullman, WA). It was propagated in Madin-Darby bovine kidney (MDBK) cells. A few days after infection, when viral cytopathic effect (CPE) included $>90 \%$ of the culture, the T-75 flasks were frozen at $-80^{\circ} \mathrm{C}$. The flasks subsequently were thawed at ambient temperature and the conditioned medium was centrifuged at 2,000 $\mathrm{rpm}$ for $15 \mathrm{~min}$. The resulting supernatant was collected, aliquoted and stored at $-80^{\circ} \mathrm{C}$. The certified titer of the stock BVDV was determined to be $7.74 \log _{10} \mathrm{TCID}_{50} / \mathrm{mL}$ in MDBK cells.

West Nile virus (WNV), strain B 956 [V-554-001-522], was obtained from American Type Culture Collection (Manassas, VA), ATCC No. VR-1267. It was propagated in BHK-21 cells. A few days after infection, when viral cytopathic effect (CPE) involved $>90 \%$ of the culture, the T-75 flasks was frozen at $-80^{\circ} \mathrm{C}$. The flasks subsequently were thawed at ambient temperature and the conditioned medium was centrifuged at 2,000 rpm for $15 \mathrm{~min}$. The resulting supernatant was collected, aliquoted and stored at $-80^{\circ} \mathrm{C}$. The certified titer of the stock WNV was determined to be $7.35 \log _{10} \mathrm{TCID}_{50} / \mathrm{mL}$ in Vero cells.

\section{Cell infectivity assays}

The infectious virus titer of test and control samples was determined by generation of viral cytopathic effect (CPE) in detector cell cultures (Vero E6 for ZIKV, MDBK for BVDV and Vero for WNV). Selected dilutions of test and control post-neutralized sample (PNS) were inoculated onto host cell cultures ( 8 wells/dilution) and the culture plates were incubated at $36 \pm 2^{\circ} \mathrm{C}$ with $5 \pm 1 \% \mathrm{CO}_{2}$ for $7-14$ days. The detector cells were then examined microscopically for the presence of viral CPE or for evidence of cytotoxicity due to disinfectants. The CPE results were used to calculate the virus titer of the challenge virus stock or PNS in units of $\mathrm{TCID}_{50} / \mathrm{mL}$.

\section{Surface inactivation studies}

One physical inactivation approach (dry heat) and seven chemical disinfectants and were evaluated at two levels of organic load $(5 \%$ serum, $90 \%$ blood), each at four contact times in duplicate $(\mathrm{n}=2$ independent trials). The test followed the general procedure outlined in the ASTM E1053-11 standard [10]. For each type of organic load, $0.4 \mathrm{~mL}$ of virus inoculum was allowed to dry onto a $4 \mathrm{in}^{2}$ area of a
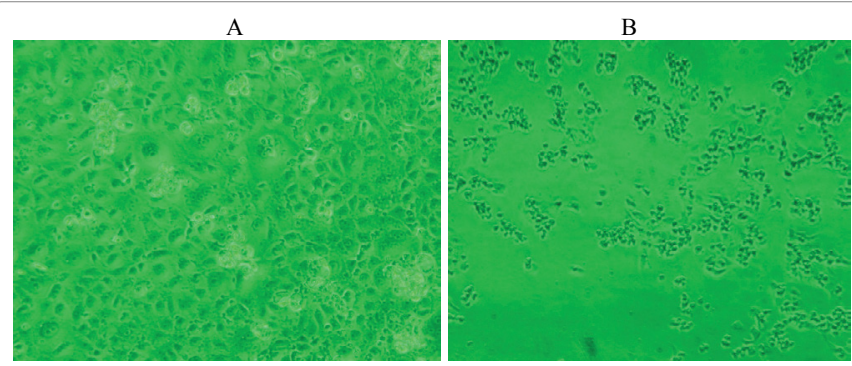

Figure 1: Microscopic appearance of (A) uninfected Vero E6 cells; (B) Vero E6 cells 10 days after infection with ZIKV glass Petri dish (carrier) at ambient temperature. After the drying period, $2.0 \mathrm{~mL}$ of the chemical disinfectant were added to the dried virus such that it completely covered the film for the duration of the contact time. For the dry heat treatment, the carriers with virus dried were placed in an incubator and held at $56^{\circ} \mathrm{C}$ or $60^{\circ} \mathrm{C}$ for the duration of the contact time. For all disinfectants, contact times of $15 \mathrm{~s}, 1 \mathrm{~min}, 2$ min and 5 min were evaluated. For dry heat, contact times of 10, 20, 60 and $120 \mathrm{~min}$ at 56 and $60^{\circ} \mathrm{C}$ were evaluated. At the completion of the contact time being evaluated, $2.0 \mathrm{~mL}(4.0 \mathrm{~mL}$ for the heat treatment) of an appropriate neutralizer were added to the carriers. The mixture was then scraped from the surface of the carriers using a cell scraper. This post-neutralization sample (PNS) was considered to be a 10 -fold dilution $\left(10^{-1}\right)$ of the original virus stock.

\section{Inactivation study controls included}

Plate recovery control (PRC): This control was performed in duplicate ( $\mathrm{n}=2$ replicates) in a manner analogous to the disinfectant test runs, with $2.0 \mathrm{~mL}$ of Dilution Medium (DM, MEM+2\% FBS) added to the dried virus in lieu of disinfectant. For the heat treatment, the control carriers were held at ambient temperature. At the completion of the contact times, these control carriers were subjected to neutralization procedures identical to those of the test coupons. Neutralizer Effectiveness/Viral Interference.

Neutralizer Effectiveness/Viral Interference Controls (NE/VI): This control was performed for each type of disinfectant at a single replicate $(n=1)$. This control was performed in an identical manner to the test runs except that $0.4 \mathrm{~mL}$ of $\mathrm{DM}$ was dried onto the carriers
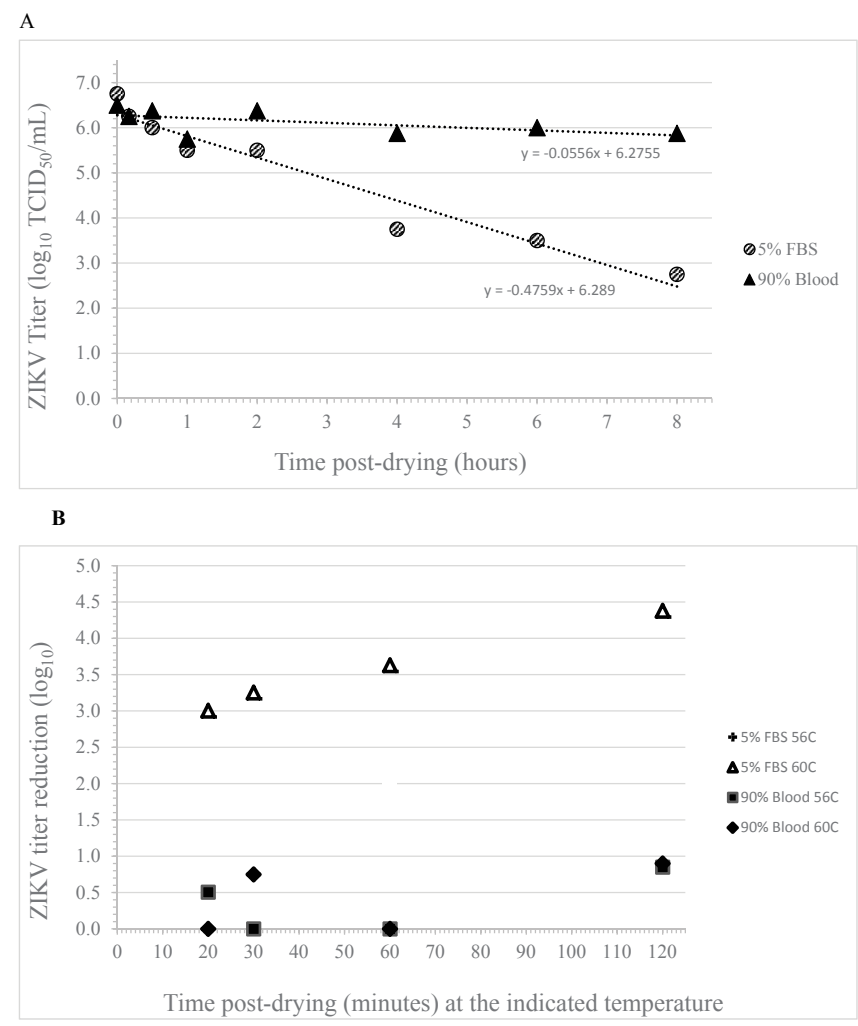

Figure 2: Thermal inactivation of ZIKV dried onto glass carriers: (A) dependence on time-post drying at ambient temperature and organic load (B) dependence on time-post drying at $56^{\circ} \mathrm{C}$ or $60^{\circ} \mathrm{C}$ and organic load Symbols indicate the mean of the results obtained from $n=2$ independent trials performed per condition. 
in lieu of virus. At the completion of the contact times, the carriers were subjected to neutralization procedures identical to those of the test carrier s. This control was then divided into two portions, one for the Cytotoxicity Control and one to continue the NE/VI. An aliquot of the NE/VI PNS was diluted using serial 10-fold dilutions. Following dilution, $0.1 \mathrm{~mL}$ of stock virus containing approximately $1,000-5,000$ infectious units of virus, was added to each dilution and held for the longest contact time prior to inoculation of host cells.

Cytotoxicity control (CT): This control was performed for each type of disinfectant at a single replicate $(n=1)$. This control was performed in a manner analogous to the NE/VI runs, except that no virus was added to the samples after serial dilution prior to the inoculation of host cells.

Cell Viability Control (CVC): This control was performed as a single replicate $(\mathrm{n}=1)$. Eight wells of host cells received only DM to demonstrate the viability of the cells throughout the assay period.

Virus stock titer control (VST): This control was performed as a single replicate $(\mathrm{n}=1)$. An aliquot of each virus stock (i.e., inoculum) was serially diluted and inoculated onto host cells to demonstrate that the titer of the virus stock used in the assay was approximately the same as the certified titer for that stock.

\section{Results}

\section{Environmental and thermal stability}

The loss of infectivity of ZIKV after being dried onto glass carriers was followed at ambient temperature to assess the environmental stability of ZIKV under laboratory and healthcare provider conditions. The results (Figure 2A) indicate a marked dependence on the organic matrix of the viral inoculum at time of deposition on the carriers. For instance, ZIKV suspended in a matrix consisting of $90 \%$ blood and dried onto carriers displayed a minimal rate of inactivation $\left(\sim 0.06 \log _{10}\right.$ per h) over the $8 \mathrm{~h}$ period, while virus suspended in culture medium containing 5\% FBS and dried onto carriers displayed inactivation at the rate of $\sim 0.5 \log _{10}$ per h over the same $8 \mathrm{~h}$ period.

The time kinetics of inactivation of ZIKV dried onto glass carriers was followed at $56^{\circ} \mathrm{C}$ and $60^{\circ} \mathrm{C}$ to assess the thermal stability of ZIKV. The results (Figure $2 \mathrm{~B}$ ) indicate that ZIKV is susceptible to dry heat when dried onto carriers in the presence of low organic load, but not in the presence of $90 \%$ blood. The thermal inactivation of ZIKV when applied to carriers in a low organic matrix and subsequently heated displayed both time and temperature dependence, with the maximum reduction in titer being $\sim 4.4 \log _{10}$ after $120 \mathrm{~min}$ at $60^{\circ} \mathrm{C}$.

\section{Chemical disinfectant efficacy}

Disinfectant efficacy for ZIKV dried onto glass carriers was evaluated per ASTM E1053-11 [4] using 90\% blood as the high organic load condition and cell culture medium containing 5\% FBS as the low organic load condition. The chemical disinfectants investigated included isopropyl alcohol, a quaternary ammonium/alcohol-based product, chlorine, peracetic acid, an acid solution ( $\mathrm{pH} 4.0)$ and an alkaline solution ( $\mathrm{pH} 10.0)$.

Isopropyl alcohol was evaluated at $70 \%$ (vol/vol) in water (Figure $3 \mathrm{~A})$. No dependence on organic load was displayed, and complete inactivation of ZIKV ( $>5 \log _{10}$ reduction in titer; the limit of detection for each condition was determined by the virus spiking and the dilution of the spiked load required to overcome interference) occurred at each contact time under both organic load conditions.

Inactivation of ZIKV by a quaternary ammonium/alcohol-based product also displayed minimal dependence on organic load (Figure $3 \mathrm{~B}$ ). In each case, $>3.5 \log _{10}$ inactivation (complete inactivation, the limit of detection for each condition was determined by the virus spiking and the dilution of the spiked load required to overcome interference) occurred within $15 \mathrm{~s}$ contact time.

In the case of chlorine, efficacy of inactivation of ZIKV dried onto glass carriers was highly dependent on the organic load present at the time of viral deposition (Figure 4A). For instance, ZIKV suspended in culture medium containing 5\% FBS and dried onto carriers was completely inactivated by chlorine concentrations as low as 500 ppm and contact times as short as $15 \mathrm{~s}$. On the other hand, ZIKV suspended in a matrix consisting of $90 \%$ blood and dried onto carriers required chlorine concentrations above $5,000 \mathrm{ppm}$ to achieve $>2 \log _{10}$ inactivation and $10,000 \mathrm{ppm}$ to achieve $>3 \log _{10}$ inactivation.

Efficacy of inactivation of ZIKV by peracetic acid (1,000 ppm) also displayed a striking dependence on organic load present at the time of deposition of the virus onto the carriers (Figure 4B). ZIKV suspended in culture medium containing 5\% FBS and dried onto carriers was completely inactivated by $1,000 \mathrm{ppm}$ peracetic acid at contact times as short as $15 \mathrm{~s}$. On the other hand, ZIKV suspended in a matrix consisting of $90 \%$ blood and dried onto carriers was inactivated $<1.5$ $\log _{10}$ by peracetic acid at contact times as high as $300 \mathrm{~s}$.

The efficacy of low (4.0) or high (10.0) pH for inactivating ZIKV dried onto glass carriers was investigated (Figure 5). Regardless of organic load (5\% FBS vs. $90 \%$ blood) present at the time of deposition

A

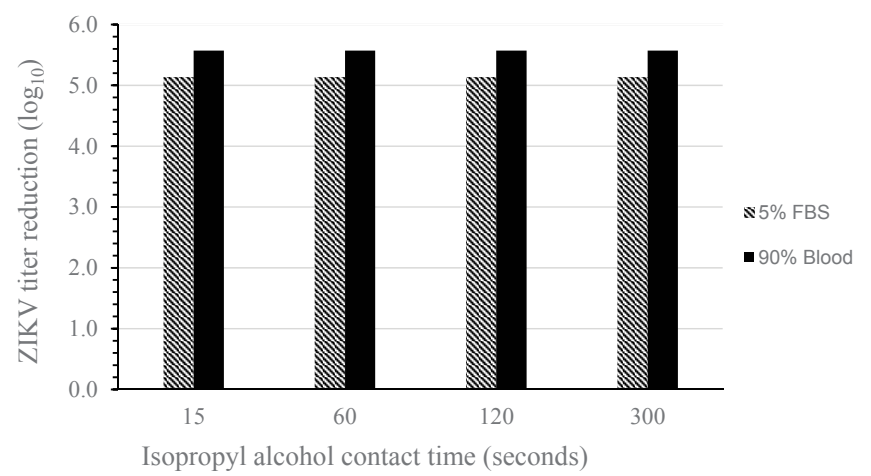

B

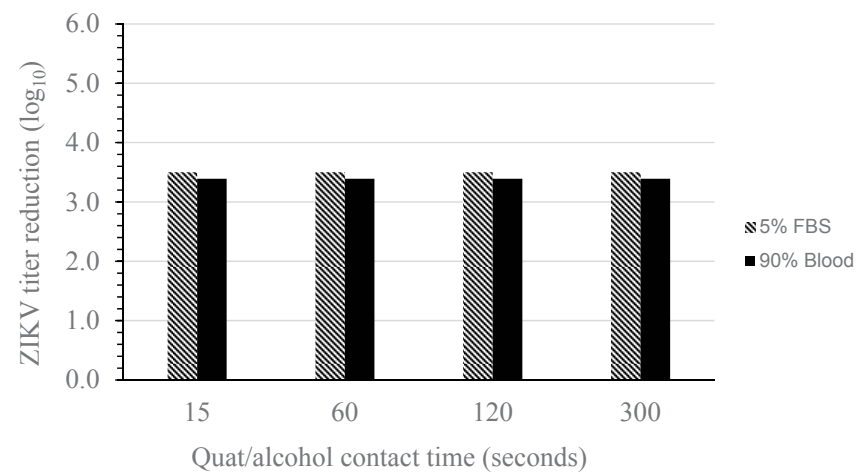

Figure 3: Inactivation of ZIKV on glass carriers by disinfectants: (A) $70 \%$ isopropyl alcohol at various contact times and organic loads; (B) a quaternary ammonium/alcohol-based product at various contact times and organic loads. Bars indicate the mean of the results obtained from $n=2$ independent trials per condition tested at ambient temperature. 

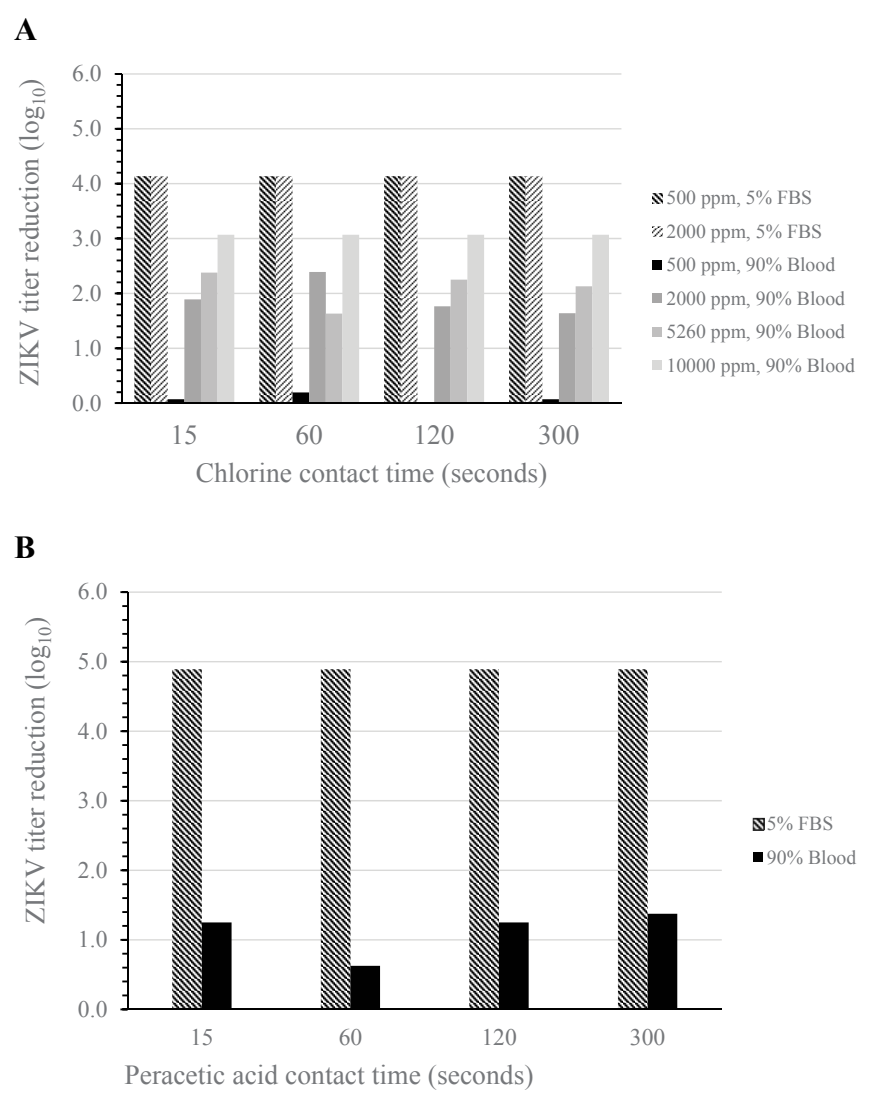

Figure 4: Inactivation of ZIKV on glass carriers by disinfectants: (A) chlorine at various concentrations, contact times and organic loads; (B) $1000 \mathrm{ppm}$ peracetic acid at various contact times and organic loads. Bars indicate the mean of the results obtained from $n=2$ independent trials per condition tested at ambient temperature.

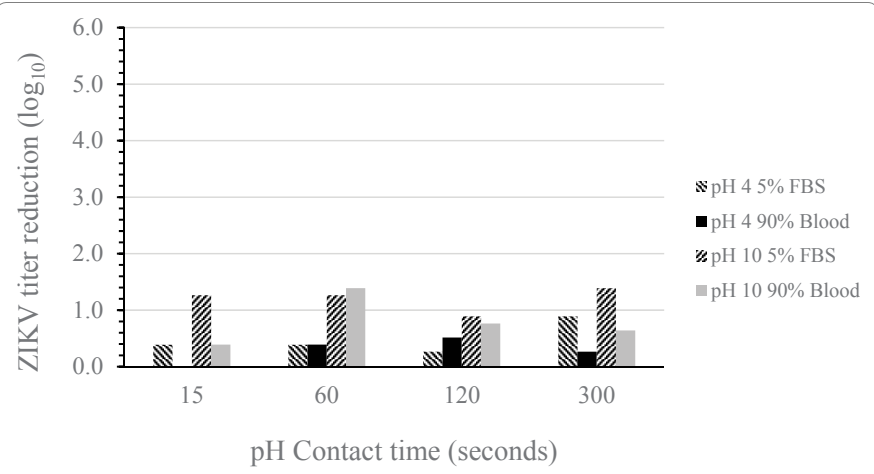

Figure 5: Inactivation of ZIKV on glass carriers at $\mathrm{pH} 4.0$ or at $\mathrm{pH} 10.0$ at various contact times and organic loads. Bars indicate the mean of the results obtained from $n=2$ independent trials per condition tested at ambient temperature.

of virus onto the carriers, the inactivating efficacy of the two $\mathrm{pH}$ solutions appeared to be minimal (i.e., $<1.5 \log _{10}$ reduction in titer). Little dependence upon contact time was displayed for the various conditions.

\section{Comparison of inactivation efficacy for ZIKV vs. other flaviviruses}

A comparison of the efficacy of various physical and chemical approaches for inactivating ZIKV and two other flaviviruses (BVDV and WNV) was enabled through conduct of side-by-side inactivation studies (Table 1). The studies shared in common the use of virus dried onto glass carriers in the presence of low (5\% FBS) or high $(90 \%$ blood) organic loads, and common reagent stocks, study personnel, and methodologies. It is apparent that dry heat at $56^{\circ} \mathrm{C}$ for $20 \mathrm{~min}$ was relatively ineffective for inactivating the three flaviviruses when these were dried onto carriers in the presence of $90 \%$ blood. When deposited onto carriers within a low organic load (5\% FBS), ZIKV appeared to be uniquely insensitive to this thermal inactivation approach, while BVDV and WNV titers were reduced by 3.4 and $2.5 \log _{10}$, respectively.

The disinfectants isopropyl alcohol (70\%) and the quaternary ammonium/alcohol product $(0.28 \%$ diisobutylphenoxy-ethoxyethyl dimethyl benzyl ammonium chloride/17.2\% isopropanol) caused complete inactivation of all flaviviruses tested within $15 \mathrm{~s}$ contact time, regardless of organic load (Table 1). Chlorine applied at 500 and $1,000 \mathrm{ppm}$ for up to $5 \mathrm{~min}$, displayed similar inactivation efficacy ( $\geq$ $3.5 \log _{10}$ reduction in titer) for the three flaviviruses deposited in a low organic matrix (5\% FBS). When deposited onto carriers within a high organic matrix (90\% blood), ZIKV and BVDV were only inactivated minimally 0.1 to $1.6 \log _{10}$, while WNV was completely inactivated ( $\geq$ $2.6 \log _{10}$ ). A similar impact of organic load at the time of virus drying onto carriers was displayed by the disinfectant peracetic acid. In this case peracetic acid at $1,000 \mathrm{ppm}$ at contact times up to $5 \mathrm{~min}$, displayed similar inactivation efficacy ( $\geq 3.5 \log _{10}$ reduction in titer) for the three flaviviruses deposited in a low organic matrix (5\% FBS). When deposited onto carriers within a high organic matrix (90\% blood), ZIKV and BVDV were only inactivated by peracetic acid minimally ( 0.6 to $1.6 \log _{10}$ ), while WNV was completely inactivated $\left(\geq 2.6 \log _{10}\right)$.

A low $\mathrm{pH}$ ( $\mathrm{pH} 4.0)$ solution had very little inactivation efficacy for any of the three flaviviruses (Table 1), while a pH 10.0 solution caused some inactivation $\left(2.0 \log _{10}\right)$ of WNV dried to the carrier within a low organic matrix (5\% FBS).

\section{Discussion}

Knowledge of the environmental stability and susceptibility to commonly available disinfectants and physical inactivation approaches for the newly emergent Zika virus is essential for assuring the safety of laboratory and healthcare workers and their facilities. Such information is also important for safeguarding the blood supply in ZIKV-infected geographic regions and to prevent opportunistic infections. In the present paper, we have characterized the ambient temperature stability of ZIKV on glass Petri dishes used as a proxy for hard non-porous environmental surfaces in general. In addition, we have evaluated the dry thermal inactivation of ZIKV at 56 and $60^{\circ} \mathrm{C}$. Finally, we have evaluated five disinfection regimens, including isopropyl alcohol, chlorine, peracetic acid, a quaternary ammonium/alcohol product, and low and high $\mathrm{pH}$ solutions for inactivation of ZIKV. All studies were performed per ASTM E1053-11 [10] in duplicate on ZIKV dried onto glass carriers in the presence of low (5\% FBS) or high ( $90 \%$ blood) organic load to mimic conditions that might be found in laboratory or healthcare facilities. The inactivation results for ZIKV have been compared to results obtained for other flaviviruses, including BVDV (genus Pestivirus) and WNV (genus Flavivirus). We have also compared our environmental stability and disinfection efficacy results to those published in the literature recently for ZIKV [11].

The environmental stability of ZIKV was found to be highly dependent on the organic load present at the time of drying of the virus onto the glass carriers. When a low organic load (5\% FBS) was present, ZIKV infectivity degraded with relatively constant rate $\left(\sim 0.5 \log _{10}\right.$ 


\begin{tabular}{|c|c|c|c|c|c|c|c|}
\hline \multirow{3}{*}{ Inactivation Regimen* } & \multirow{3}{*}{ Contact Time } & \multicolumn{6}{|c|}{ Inactivation efficacy $(\log 10$ reduction in titer) $\dagger$} \\
\hline & & \multicolumn{2}{|c|}{ ZIKV§ } & \multicolumn{2}{|c|}{ BVDV } & \multicolumn{2}{|c|}{ WNV } \\
\hline & & $5 \%$ FBS & $90 \%$ Blood & $5 \%$ FBS & $90 \%$ Blood & $5 \%$ FBS & $90 \%$ Blood \\
\hline Dry heat $\left(56^{\circ} \mathrm{C}\right)$ & $20 \mathrm{~min}$ & 0.5 & 0.1 & 3.4 & 0.1 & 2.5 & 1.1 \\
\hline Isopropyl alcohol (70\%) & $15 \mathrm{~s}$ & $\geq 5.1 \pi$ & $\geq 5.6$ & $\geq 4.3$ & $\geq 3.3$ & $\geq 3.5$ & $\geq 2.6$ \\
\hline Quaternary ammonium/alcohol & $15 \mathrm{~s}$ & $\geq 3.5$ & $\geq 3.4$ & $\geq 4.3$ & $\geq 3.3$ & $\geq 3.5$ & $\geq 2.6$ \\
\hline Chlorine (500 ppm) & $5 \mathrm{~min}$ & $\geq 4.1$ & 0.1 & 3.7 & 0.4 & $\geq 3.5$ & $\geq 2.6$ \\
\hline Chlorine (1000 ppm) & $5 \min$ & $\geq 4.1$ & 1.6 & 4.0 & 0.6 & $\geq 3.5$ & $\geq 2.6$ \\
\hline Peracetic acid (1000 ppm) & $5 \mathrm{~min}$ & $\geq 4.9$ & 1.4 & 3.8 & 1.2 & $\geq 3.5$ & $\geq 2.6$ \\
\hline $\mathrm{pH} 4.0$ & $5 \min$ & 0.9 & 0.3 & 1.1 & 0.1 & 1.4 & 0.3 \\
\hline $\mathrm{pH} 10.0$ & $5 \mathrm{~min}$ & 1.4 & 0.6 & 1.0 & 0.1 & 2.0 & 1.3 \\
\hline
\end{tabular}

All treatments were initiated post-drying of the virus in the indicated organic matrix onto glass carriers

tValues shown represent the mean of the results obtained from two independent trials

§Abbreviations used: BVDV, Bovine Viral Diarrhea Virus; FBS, Fetal Bovine Serum; WNV, West Nile Virus; ZIKV, Zika Virus

"Values specified as " $\geq$ " represent complete inactivation, where the limit of detection for the particular condition was determined by the TCID ${ }_{50}$ assay format, virus spiking, and the dilution of the spiked load required overcoming cytotoxicity or interference, if present

Table 1: Comparison of inactivation of the flaviviruses ZIKV, BVDV and WNV on glass carriers by dry heat, disinfectants or low/high $\mathrm{pH}$

per h) under ambient conditions. Müller et al. [11] also investigated the environmental stability of ZIKV (MR 766 strain) dried for $18 \mathrm{~h}$ onto the surface of 24-well cell culture plates and then reconstituted with phosphate buffered saline. In their study, $\sim 3 \log _{10}$ degradation of ZIKV was observed over the $18 \mathrm{~h}$ period, for an estimated rate of $\sim 0.2$ $\log _{10}$ titer reduction per hour. This degradation rate is lower than the rate observed in our study $\left(\sim 0.5 \log _{10}\right.$ per h), but the accuracy of the estimated degradation rate from [11] cannot be ascertained fully due to only two data points (time ${ }_{0}$ and time ${ }_{18 \mathrm{~h}}$ ) being generated. Müller et al. did not evaluate the impact of organic load at the time of drying of the virus on the environmental stability. Doerrbecker et al. [12] reported that the survival of another flavivirus (hepatitis $\mathrm{C}$ virus, $\mathrm{HCV}$; genus Hepacivirus) was actually reduced by approximately $1.0-1.5 \log _{10}$ when dried in the presence of an organic load (human serum). It remains to be confirmed whether the survivability of HCV is positively or negatively impacted by blood.

The inactivating efficacies of dry heating at $56^{\circ} \mathrm{C}$ and $60^{\circ} \mathrm{C}$ and of certain disinfectants, including chlorine and peracetic acid, were also found to be highly dependent on the organic load present at the time of drying of the virus onto the carriers. ZIKV in a $90 \%$ blood matrix was notably more stable at $56^{\circ} \mathrm{C}$ and $60^{\circ} \mathrm{C}$ than it was under $5 \% \mathrm{FBS}$, suggesting a stabilizing or protective effect from the blood. Similarly, when ZIKV was suspended in $90 \%$ blood at the time of application to the carriers, there appeared to be a protective effect conferred onto the virus for chlorine and peracetic acid treatments. This apparent protective effect was also observed for the flavivirus BVDV in the present study. Interestingly, the protective effect of organic load for chlorine and peracetic acid inactivation was not observed for another flavivirus (WNV) examined in this study. In this regard, our results with WNV were similar to those described previously for the flavivirus hepatitis C [12]. Doerrbecker et al. [12] dried HCV onto stainless steel coupons in the absence or presence of $50 \%$ human serum as organic load, and then subjected the virus to a series of alcohols and disinfectant products, including quaternary ammonium compounds and peroxides. The data indicated that the human serum did not confer resistance to alcohols and other biocides tested for HCV. Based on our ambient temperature and heat inactivation data, which involved no chemicals, and the chlorine and peracetic acid results, it would appear that organic load, such as blood, in viral inoculum may confer protection to ZIKV in two ways. It may stabilize ZIKV through protein binding, maintaining viral particle organization on the environmental surface, changing the distribution and layout of virus on the surface or forming a protective layer on top of the virus particles. Additionally, the organic load can also react with the active ingredients of certain disinfectants (such as chlorine or peracetic acid) to reduce their effective concentrations. Higher organic load would be expected to negatively impact the efficacy of a disinfectant, except those disinfectants that are not sensitive to organics, such as alcohol.

In our studies, the protective effect of high organic load did not apply to isopropyl alcohol (70\%) or the quaternary ammonium/alcohol product. In either case, the inactivation of ZIKV virus was complete within $15 \mathrm{~s}$ contact time. The insensitiveness to organic loads of these chemicals may be attributable to their respective viral inactivation mechanisms. Similar results were obtained for two additional flaviviruses examined, BVDV and WNV. Isopropyl alcohol was also found to be very effective for inactivating hepatitis $C$ virus when dried onto steel coupons in the presence or absence of human serum [12]. In either case, concentrations of isopropyl alcohol as low as $40 \%$ reduced the titer of hepatitis $C$ virus $>4 \log _{10}$ within 5 min contact time. Müller et al. [11] reported that isopropyl alcohol (70\%) completely inactivated (from $>6 \log _{10} / \mathrm{mL}$ input virus) ZIKV that had been dried onto a plastic surface. It would be of interest to compare the resistance of ZIKV to other arboviruses such as Dengue fever virus, yellow fever virus, Japanese encephalitis virus and Chikungunya viruses, etc.

Our data indicating minimal efficacy of $\mathrm{pH} 10.0$ solutions for inactivating ZIKV dried onto glass carriers is in agreement with the solution inactivation results of Müller et al. [11]. On the other hand, those authors reported a complete inactivation of ZIKV after the viral stock was adjusted to $\mathrm{pH} 4$ and held for $10 \mathrm{~min}$ in solution inactivation studies. Our studies in which dried ZIKV was reconstituted in a $\mathrm{pH}$ 4.0 solution for $5 \mathrm{~min}$ resulted in $<1 \log _{10}$ inactivation, regardless of the organic load. It is not clear whether the differences in efficacy are more related to differences in contact time or treatment approach (e.g. effective $\mathrm{pH}$ during exposure). Our results indicated minimal efficacy for $\mathrm{pH} 4.0$ and $\mathrm{pH} 10.0$ inactivation of each of the flaviviruses examined (ZIKV, BVDV, and WNV). These results are in agreement with those of Depner et al. [13], who reported that the half-life of BVDV in $\mathrm{pH} 4$ solutions at $21^{\circ} \mathrm{C}$ was $18 \mathrm{~h}$ for the non-cytopathic strain New York 1 and 25 hours for the cytopathic strain NADL.

Another apparent difference between the results of Müller et al. [11] and those from this study is in regard to the efficacy for thermal inactivation. In the glass carrier/dry heat studies that we performed, ZIKV was inactivated to a moderate extent $\left(\sim 3\right.$ to $\left.4.5 \log _{10}\right)$ at $60^{\circ} \mathrm{C}$ and contact times of 20 to $120 \mathrm{~min}$. On the other hand Müller et al observed complete inactivation (from $>6 \log _{10} / \mathrm{mL}$ input virus) within 
Citation: Wilde C, Chen Z, Kapes T, Chiossone C, Lukula S, et al. (2016) Inactivation and Disinfection of Zika Virus on a Nonporous Surface. J Microb Biochem Technol 8: 422-427. doi: 10.4172/1948-5948.1000319

5 minutes at $60^{\circ} \mathrm{C}$ in their solution inactivation study [11]. It has been reported that dry heating on surfaces is less effective than heating of viruses suspended in solutions (referred to by some authors as moist heating) for inactivating virus [11]. Further work is required to determine if this is true in general or if this applies only to certain virus types, carrier types, and organic loads present at the time of drying of virus onto carriers.

\section{Conclusion}

Results of surface inactivation studies performed with ZIKV alongside other flaviviruses such as BVDV and WNV indicate that ZIKV could remain viable for a prolonged time in the environment, especially in a blood matrix. The results indicate that in most respects, ZIKV displays susceptibility to commonly employed disinfectants similar to that of other flaviviruses. However, the presence of a heavy organic load such as blood may offer marked protection to ZIKV to heat and certain disinfectants. Additionally, ZIKV appears to be less susceptible to $56^{\circ} \mathrm{C}$ than BVDV or WNV. Our results for ZIKV complement other recent reports describing efficacy of chemical and physical inactivation approaches for this newly emergent virus [11,14]. The results should aid in the development of appropriate disinfection and sanitization regimens and products.

\section{References}

1. Prisant N, Bujan L, Benichou H, Hayot PH, Pavili L, et al. (2016) Zika virus in the female genital tract. Lancet Infect Dis 16: 1000-1001.

2. Campos R, Cirne-Santos C, Meira GLS, Santos LLR, de Meneses MD, et al. (2016) Prolonged detection of Zika virus RNA in urine samples during the ongoing Zika virus epidemic in Brazil. J Clin Virol 77: 69-70.

3. Bingham AM, Cone M, Mock V, Heberlein-Larson L, Stanek D, et al. (2016)
Comparison of test results for Zika virus RNA in urine, serum and saliva specimens from persons with travel-associated Zika virus disease - Florida 2016. MMWR Morb Mortal Wkly Rep 65: 475.

4. Bonaldo MC, Ribeiro IP, Lima NS, dos Santos AAC, Menezes LSR, et al. (2016) Isolation of infective Zika virus from urine and saliva of patients in Brazil. PLoS Negl Trop Dis 10:e0004816.

5. Atkinson B, Hearn P, Afrough B, Lumley S, Carter D, et al. (2016) Detection of Zika virus in semen. Emerg Infect Dis 22: 940.

6. Harrower J, Kiedrzynski T, Baker S, Upton A, Rahnama F, et al. (2016) Sexual transmission of Zika virus and persistence in semen, New Zealand. Emerg Infect Dis 22: 940.

7. Turmel JM, Abgueguen P, Hubert B, Vandamme YM, Maquart M, et al. (2016) Late sexual transmission of Zika virus related to persistence in the semen. Lancet 387: 2501.

8. Mansuy JM, Dutertre M, Mengelle C, Fourcade C, Marchou B, et al. (2016) Zika virus: High infectious viral load in semen, a new sexually transmitted pathogen? Lancet Infect Dis 16: 405.

9. http://www.cdc.gov/zika/transmission.

10. ASTM E1053-11 (2011) Standard test method to assess virucidal activity of chemicals intended for disinfection of inanimate, non-porous environmental surfaces, ASTM International, West Conshohocken, PA.

11. Müller JA, Harms M, Schubert A, Jansen S, Michel D, et al. (2016) Inactivation and environmental stability of Zika virus. Emerg Inf Dis.

12. Doerrbecker J, Friesland M, Ciesek S, Erichsen TJ, Mateu-Gelabert P, et al (2011) Inactivation and survival of hepatitis $C$ virus on inanimate surfaces. J Inf Dis 204: 1830-1838.

13. Depner K, Bauer T, Liess B (1992) Thermal and pH stability of pestivirus. Rev Sci Tech Off Int Epiz 11: 885-893.

14. Richard V, Green J, Broult J, Musso D (2016) Inactivation of Zika virus in plasma with amotosalen and ultraviolet A illumination. Transfusion 56: 33-40. 